Жигунова Галина Владимировна

доктор социологических наук, доцент, профессор кафедры философии, социальных наук и права социального обеспечения Мурманского арктического государственного университета

\section{БАРЬЕРИЗАЦИЯ ИНВАЛИДНОСТИ КАК ПРОБЛЕМА РОССИЙСКИХ ПОСЕЛЕНИЙ (НА ПРИМЕРЕ МУРМАНСКОЙ ОБЛАСТИ) [1]}

\section{Аннотация:}

В статье представлены результаты исследования барьеризации инвалидности как историко культурного процесса, вследствие которого в российском обществе существует проблема доступности социальной среды для людей с инвалидностью. Из-за существующих социальных барьеров люди с инвалидностью не могут вести независи мый образ жизни и реализовать свои права, что свидетельствует об актуальности проблемы. В статье выявляется уровень доступности/барьеризации объектов социальной инфраструктуры в городских и сельских поселениях Мурманской области. Исследование, проведенное в 2018-2019 ге. под руководством и с участием автора на основе метода наблюдения, показало, что создание доступной среды в регионе осуществляется крайне неравномерно по различным сферам и типам населенных пунктов. Проблема создания доступной среды решается лучше в городских поселениях, однако большинство объектов социальной инфраструктуры не готово для людей с инвалидностью даже наполовину.

\section{Ключевые слова:}

инвалидность, доступная среда, социальные барьеры, барьеризация инвалидности, городская инфраструктура, сельская инфраструктура, Мурманская область.

\section{Zhigunova Galina Vladimirovna}

D.Phil. in Sociology, Associate Professor, Professor, Department of Philosophy, Social Sciences and Social Security, Murmansk Arctic State University

\section{BARRIERS FOR PEOPLE WITH DISABILITIES AS A PROBLEM OF RUSSIAN SETTLEMENTS (AS EXEMPLIFIED BY THE MURMANSK REGION) [1]}

Summary:

The article presents the results of the study of presence of barriers for people with disabilities as a historical and cultural process, which lead to the problem of accessible social environment for people with disabilities in Russia. Due to existing social barriers people with disabilities cannot lead an independent lifestyle and exercise their rights, which indicates the relevance of the problem under consideration. The article examines the level of accessibility/presence of barriers with regard to the social infrastructure in urban and rural settlements of the Murmansk region. The study conducted in 2018-2019 under the guidance and with participation of the author on the basis of an observation method has shown that the creation of an accessible environment in the region is extremely uneven depending on different areas and types of settlements. The problem of creating an accessible environment is better solved in urban areas, but most social infrastructure facilities are not even half ready for people with disabilities.

Keywords: disability, accessible environment, social barriers, barriers for people with disabilities, urban infrastructure, rural infrastructure, the Murmansk region.

Инвалидность является одной из распространенных социальных проблем современного общества. В результате устойчивых фризических, психических, интеллектуальных или сенсорных нарушений, приведших к инвалидности, граждане не могут эффективно участвовать в жизни общества и реализовывать свой потенциал. Инвалидность при этом рассматривается как не только медицинский френомен, но и социальный, поскольку затрагивает множество социальных институтов, принципов организации социальной среды и социальных связей.

Современное понимание инвалидности неразрывно связано с наличием в обществе социальных барьеров, препятствующих людям с инвалидностью в реализации их гражданских прав и ведении независимой жизни. Барьеризация инвалидности выступает процессом, в ходе которого в обществе осознанно или неосознанно создаются условия, лишающие людей с инвалидностью равных возможностей с условно здоровыми людьми. Указанный процесс связан с историческим развитием общества и практикой организации социальной среды и социальных взаимодействий в тех или иных культурных условиях.

Сами барьеры изменяются с развитием общества и могут принимать скрытые или явные формы. Однако все они лишают доступа к социальным ресурсам и благам, которыми пользуются люди, не имеющие проблем со здоровьем. 
Особое место среди барьеров инвалидности занимают средовые барьеры, обусловленные в первую очередь недоступностью социальной инфраструктуры, не позволяющей людям с сенсорными нарушениями перемещаться в физическом пространстве и иметь доступ к каким-либо объектам и услугам.

Во Всемирной программе действий в отношении инвалидов, принятой Генеральной Ассамблеей ООН в 1982 г., показана ключевая роль среды как фактора, определяющего влияние дефекта или инвалидности на повседневную жизнь человека. В результате барьеров социальной и фризической среды люди с инвалидностью не могут вести независимый образ жизни и находятся в сегрегированном и дискриминируемом положении. «Человек неполноценен, - указывается в этом документе, - если он лишен возможностей, обычно имеющихся в обществе... включая семейную жизнь, образование, занятость, жилье, финансовую и личную безопасность, участие в социальных или политических группах, религиозную деятельность, интимные и половые отношения, доступ ко всем видам общественного обслуживания, свободу передвижения и общий образ повседневной жизни» [2].

В 9-й статье Конвенции о правах инвалидов говорится о необходимости обеспечения инвалидам доступа наравне с другими к физическому окружению, транспорту, информации и связи, включая информационно-коммуникационные технологии и системы, а также к другим объектам и услугам, открытым или предоставляемым для населения как в городских, так и сельских районах [3].

Создание доступной социальной среды для людей, имеющих инвалидность, дает им возможность быть интегрированными в общество, вести независимый образ жизни, реализовать себя в личностном плане, трудовой деятельности и снижает экономическую нагрузку на остальное население.

В российском обществе исторически сложилось, что люди с инвалидностью рассматривались в первую очередь как объекты опеки, но не независимые субъекты, нуждающиеся в специально обустроенной среде для равного участия в жизни общества. Традиционно им оказывались помощь и поддержка в виде частных практик, существовавших еще у славян в древнейшем периоде, затем в рамках церковно-монастырской помощи, с XVII в. - посредством государственного и государственно-общественного призрения, с XX в. - системы социального обеспечения и социального страхования и т. п. Благодаря указанным практикам и сложившейся системе помощи инвалидам в СССР сформировалась патерналистская модель социальной защиты, в рамках которой люди, имеющие инвалидность, получали определенные пенсии и льготы, тогда как инфраструктура поселений, общественных и жилых зданий, транспорта не позволяла им включаться в жизнь сообществ, а сами люди с инвалидностью воспринимались как бесполезные для социума.

Политику государства, проводимую в советский период, Г.А. Кабакович и К.В. Полежаева характеризуют тезисом «инвалидов у нас нет», транслируемым в советском обществе. Такое отношение к инвалидам, по мнению авторов, до сих пор остается устойчивым в сознании многих людей [4]. В.А. Фефрелов в книге «В СССР инвалидов нет!..» на основе наблюдений, анализа документов и биографических интервью приводит многочисленные свидетельства бесправного положения инвалидов в советский период, равнодушного отношения к ним, пишет о чувстве собственной ненужности и беспомощности, которые испытывали люди с инвалидностью [5, с. 96].

К 2000-м гг. ситуация в России стала меняться, особенно в связи с ратификацией Конвенции о правах инвалидов в 2008 г. [6], в результате чего был принят ряд нормативно-правовых документов, направленных на создание условий для обеспечения равных прав инвалидов. Особенно следует отметить Федеральный закон № 419-Ф3 «О внесении изменений в отдельные законодательные акты Российской Федерации по вопросам социальной защиты инвалидов в связи с ратификацией Конвенции о правах инвалидов» от 1 декабря 2014 г., вступивший в силу 1 января 2016 г. [7], в котором скорректированы 25 нормативных правовых актов по вопросам социальной защиты инвалидов и требований доступа к объектам инфраструктуры; Порядок обеспечения условий доступности для инвалидов объектов и предоставляемых услуг в сфере труда, занятости и социальной защиты населения, а также оказания им при этом необходимой помощи (Приказ Минтруда России № 527н от 30 июля 2015 г. [8]) и др.

В Федеральном законе № 181-Ф3 «О социальной защите инвалидов в Российской Федерации» (ред. от 01.12.2014 г.) в статье 15 говорится об обеспечении беспрепятственного доступа инвалидов к объектам социальной, инженерной и транспортной инфраструктуры - жилым, общественным и производственным зданиям, строениям и сооружениям, местам отдыха и предоставляемым в них услугам. Обеспечение доступа к объектам и услугам входит в обязанность фредеральных органов государственной власти, органов государственной власти субъектов Российской Федерации, органов местного самоуправления и организаций, независимо от их организационно-правовых форм [9]. 
С целью увеличения доли доступных объектов социальной, транспортной, инженерной инфраструктуры для маломобильных категорий граждан и инвалидов в 2011 г. была принята государственная программа «Доступная среда», действующая в настоящее время и рассчитанная до 2025 г. [10]. В рамках данной программы меры по созданию доступной среды осуществляются в приоритетных сфрерах жизнедеятельности: здравоохранение, культура, транспортная и пешеходная инфраструктура, информация и связь, образование, социальная защита, занятость, спорт и физическая культура. Российское законодательство предусматривает обеспечение доступа инвалидов к объектам и местам предоставления услуг в поселениях различного типа.

Таким образом, благодаря мерам российской государственной социальной политики, принимаемым для интеграции инвалидов в общество, в последнее десятилетие социальная среда целенаправленно преобразуется.

Однако данный процесс находится еще в середине пути. По результатам экспертного интервью, проведенного под руководством и с участием автора в 2018 г. среди специалистов социальных учреждений и служб Мурманской области $(\mathrm{N}=184)$, выявлено, что люди с инвалидностью в регионе имеют доступ лишь к некоторым приоритетным объектам, тогда как большинство объектов инфраструктуры им недоступно. По мнению экспертов, сами инвалиды не интегрированы в социум даже наполовину [11, с. 26].

Анализ государственной программы «Доступная среда» на 2011-2015 гг. А.А. Никоновой в пилотных регионах показал, что приоритеты создания безбарьерной среды локальны и ситуативны. В зависимости от тех или иных причин, одни субъекты Федерации около или более половины средств направили на адаптацию транспортной инфраструктуры (Тверская область, Республика Хакасия), другие - учреждений здравоохранения (Тверская область и Республика Татарстан), третьи - объектов социальной защиты (Саратовская область, Удмуртская Республика, Республика Татарстан) [12, с. 10].

По результатам исследования уровня доступности социальной среды для инвалидов А.А. Шабуновой и Л.Н. Фахрадовой в Вологодской области выявлено, что большие трудности в вопросе доступа для людей с нарушениями зрения имеют объекты спорта, образования, культуры и жилого фонда, для людей с опорно-двигательными нарушениями - объекты спорта, культуры, образования $[13$, с. 8]. Возможными причинами существования барьеров авторы считают непродуманную градостроительную политику; недостаток средств для переоборудования объектов инфраструктуры, закупки низкопольного общественного транспорта; слабый контроль выполнения установленных норм по доступности архитектурных объектов для инвалидов при строительстве; незаинтересованность общества в решении проблем инвалидов; отсутствие последовательной программы мероприятий, направленных на расширение спектра актуальных источников информации, доступных для инвалидов [14, с. 11].

Приведенные результаты исследований подтверждают актуальность проблемы создания доступной среды для инвалидов в российском обществе.

В решении проблемы доступности социальной среды для людей с ограниченными возможностями здоровья может быть интересен зарубежный опыт. Удачным примером создания инклюзивного (универсального) дизайна в городе является площадь генерала Гордона в Лондоне, спроектированная ландшафтным архитектором Густафсоном Портером в 2011 г., позволяющая всем ее посетителям на равных участвовать в жизни общества [15].

С целью выявления состояния и уровня доступности объектов социальной инфраструктуры в городских и сельских поселениях Мурманской области в 2018-2019 гг. под руководством и при участии автора было проведено наблюдение в 7 городах и городских поселениях региона: Апатиты, Заполярный, Кандалакша, Кола, Мончегорск, Никель, Североморск, а также в 6 сельских поселениях: Алакуртти, Варзуга, Корзуново, Ловозеро, Пушной, Териберка, расположенных в разных частях области и в совокупности представляющих все муниципальные образования региона. Выборка целенаправленная, в сельских поселениях со стопроцентным охватом общественных объектов и учреждений, в городах - выборочным.

Следует отметить, что Мурманская область относится к наиболее урбанизированным территориям России, где доля городского населения составляет 92,2 \% (690 тыс. чел.), а сельского 7,8 \% (58,1 тыс. чел.) [16]. В Мурманской области по состоянию на июнь 2019 г. проживало 28508 инвалидов и 2719 детей-инвалидов [17]. Места проживания данных лиц неравномерно распределены как по городским, так и по сельским населенным пунктам.

В процессе наблюдения предполагалось, что процессы создания доступной среды в российских регионах (на примере Мурманской области) происходят неравномерно и преимущественно ориентированы на преобразование городской инфрраструктуры в связи с происходящими урабанизационными процессами. 
В ходе наблюдения был осуществлен осмотр входов в здания и оценена доступность объектов инфраструктуры для отдельных категорий людей с инвалидностью, нуждающихся в специальных условиях среды (инвалидов-колясочников, людей с нарушениями опорно-двигательного аппарата и с нарушениями зрения). Внимание уделялось наличию и качеству специального оборудования для доступа людей с указанными нарушениями в здания (пандусов, перил, кнопок вызова), состоянию дверных проемов, дверей и дверных ручек, наличию места перед дверьми, тактильных полос, табличек со шрифтом Брайля и т. п.

Наблюдаемые объекты относились как к приоритетным (учреждения социальной защиты и социального обслуживания населения, образовательные учреждения, учреждения дополнительного образования, здравоохранения, культуры, объекты физической культуры и спорта, транспорта и путей сообщения), так и неприоритетным сферам деятельности, среди них - магазины, супермаркеты, торговые центры, банки, учреждения сервиса и сферы услуг (парикмахерские, гостиницы и т. п.), заведения общественного питания, почтовые отделения, прочие учреждения (здания администрации, различных ведомств и организаций, ЗАГСа, полиции, нотариальных контор и т. д.), детские площадки, пешеходные дорожки и тротуары.

По результатам исследования объекты были распределены на доступные, условно доступные и недоступные. В категорию доступных были отнесены объекты, удовлетворяющие всем требованиям доступности хотя бы одной из указанных категорий инвалидов.

Всего наблюдением был охвачен 701 объект инфраструктуры (по состоянию на 30 мая 2019 г.), из которых в городских поселениях - 569 объектов, в сельских - 132. Из них 266 объектов относились к приоритетным (216 - в городских поселениях, 50 - в сельских).

По итогам наблюдения выявлено, что всего в обследуемых населенных пунктах для людей с инвалидностью доступно 143 объекта (20,4 \%), условно доступно - 102 (14,6\%), недоступно 456 объектов инфраструктуры (65\%).

Среди городских объектов инфраструктуры выявлено 23,7 \% доступных для людей с инвалидностью, 16,2 \% условно доступных, 60,1 \% недоступных. Среди доступных объектов подавляющее большинство ориентировано на людей с опорно-двигательными нарушениями и инвалидов-колясочников. Для лиц с нарушениями зрения доступно всего 6 \% объектов.

В сельских поселениях доступных объектов инфраструктуры всего $6 \%$, условно доступных - 7,6 \%, недоступных - 86,4 \% объектов. Для лиц с нарушениями зрения доступен лишь 1 \% объектов (рис. 1).

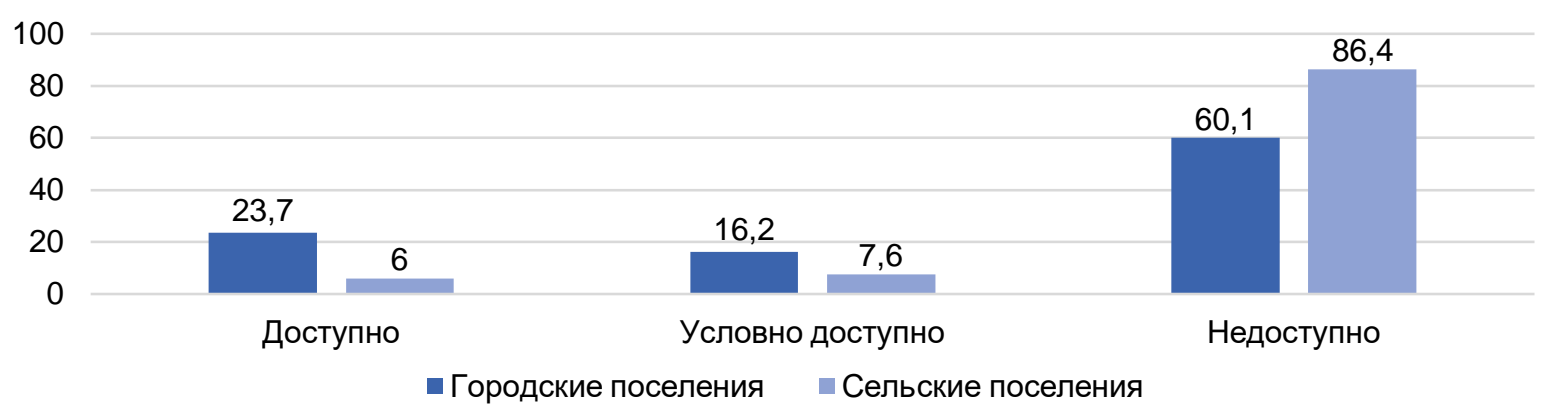

\section{Рисунок 1 - Уровень доступности объектов инфраструктуры для людей с инвалидно- стью в Мурманской области, \%}

Если сравнивать уровень доступности объектов для людей с инвалидностью в приоритетных и неприоритетных сферах, то в городских поселениях данный уровень несколько выше в неприоритетных сфрерах жизнедеятельности: доступных и условно доступных объектов 24,4 \% и $16,7 \%$ соответственно от общего количества приоритетных (рис. 2). Индекс недоступности приоритетных и неприоритетных объектов городской инфраструктуры региона составил -0,39 и -0,3 соответственно. 


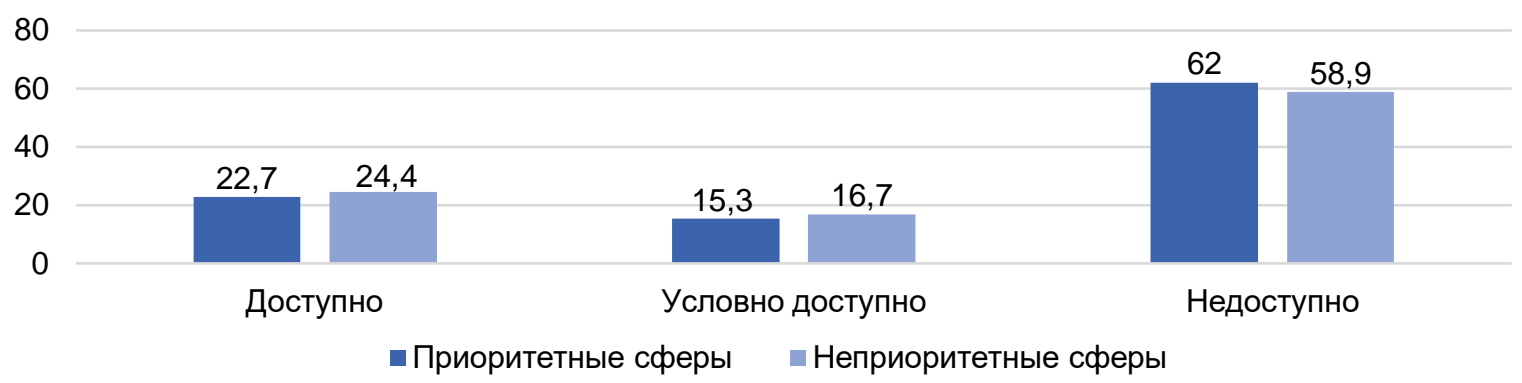

Рисунок 2 - Состояние доступности городских объектов инфраструктуры Мурманской области в приоритетных и неприоритетных сферах, \%

В сельских поселениях, напротив, уровень доступности объектов в приоритетных сферах превалирует над неприоритетными. Из всех доступных объектов в приоритетных сфрерах доступно $8 \%$, в неприоритетных - 4,9\%, условно доступно - 14 и 3,6 \% соответственно (рис. 3). Индекс недоступности приоритетных и неприоритетных объектов сельских поселений составил $-0,7$ и $-0,87$ соответственно.

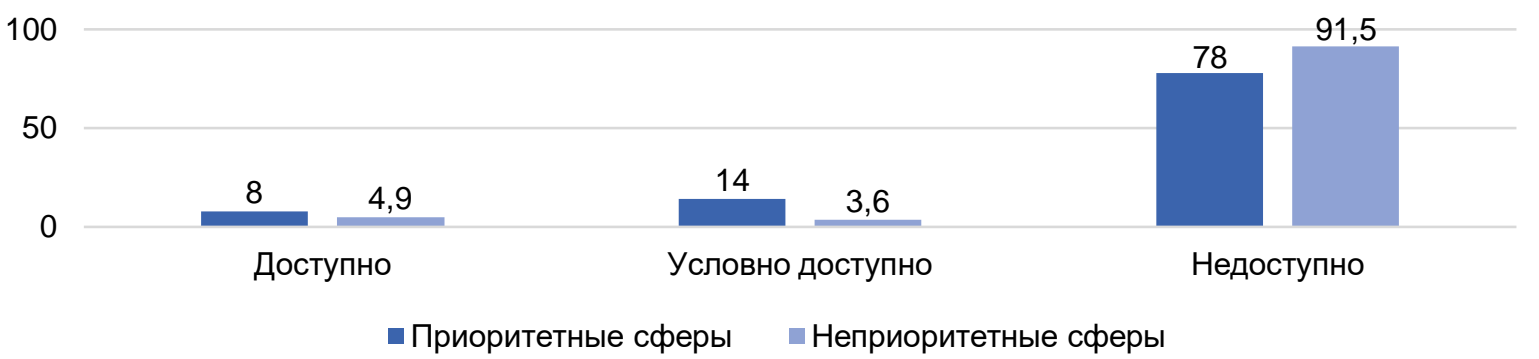

\section{Рисунок 3 - Состояние доступности сельских объектов инфраструктуры Мурманской области в приоритетных и неприоритетных сферах, \%}

Рассмотрим далее состояние объектов социальной инфраструктуры в городских и сельских населенных пунктах Мурманской области по сферам жизнедеятельности, представленное в пересчете на индексы (где 1 - полностью доступно, -1 - полностью недоступно, 0 - наполовину доступно/недоступно) (рис. 4).

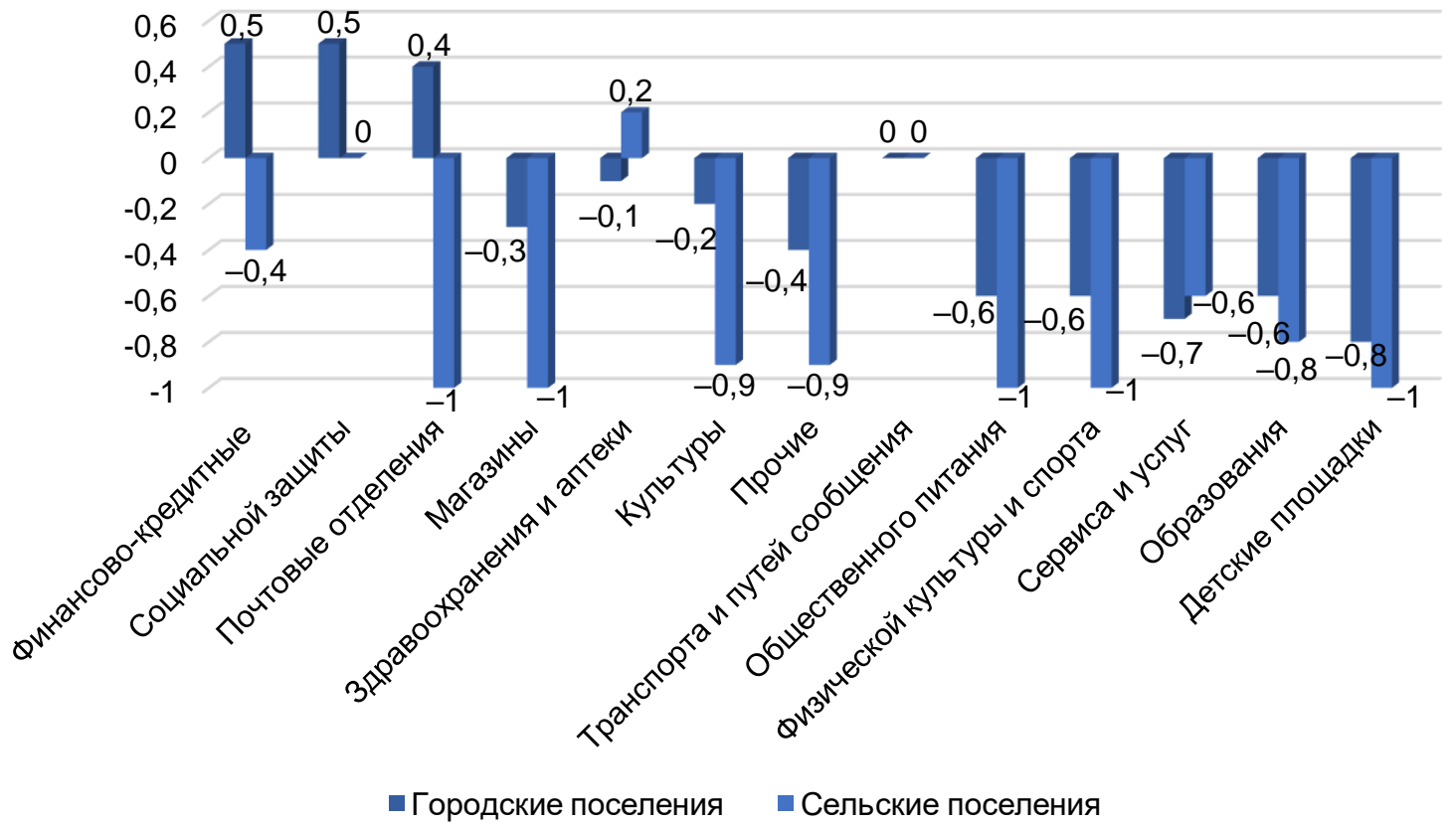

Рисунок 4 - Индексы доступности (недоступности) объектов инфраструктуры городских и сельских поселений Мурманской области 
В городских поселениях положительным индексом доступности обладают учреждения социальной защиты и социального обслуживания населения, финансово-кредитные организации (банки) (индексы по 0,5), а также учреждения почтовой связи $(0,4)$; в сельских - учреждения здравоохранения $(0,2)$. Все остальные сферы имеют отрицательный индекс, за исключением зданий транспорта и путей сообщения (здания вокзалов и автовокзалов) и учреждений социальной защиты в сельских поселениях, которые имеют нейтральный индекс.

Меньше всего доступны в городских поселениях детские площадки (индекс -0,8), учреждения сервиса и бытовых услуг $(-0,7)$, образования, фризкультуры и спорта, общественного питания (по -0,6). Полностью недоступны в сельских поселениях региона детские площадки, учреждения общественного питания, физической культуры и спорта, почтовые отделения, магазины (по -1), в большей мере малодоступны учреждения культуры и различных ведомств (по -0,9) образования $(-0,8)$, услуг и сервиса $(-0,6)$.

Таким образом, в сельских населенных пунктах уровень барьеризации объектов инфраструктуры значительно выше, чем в городских. Общий индекс барьеризации по городскими сельским поселениям составил $-0,364$ и $-0,804$ соответственно.

Приведенные данные показывают, что состояние среды в плане ее доступности для инвалидов в Мурманской области неудовлетворительное во всех типах населенных пунктов, однако оно в 2,2 раза хуже в сельских поселениях по сравнению с городскими. Подавляющее число объектов большинства сфер, за исключением учреждений социальной защиты, банковских офисов, почтовых отделений в городских поселениях и учреждений здравоохранения и аптек в сельских населенных пунктах, недоступны для лиц с инвалидностью.

Основными проблемами городской и сельской инфрраструктуры региона являются отсутствие пандусов или несоблюдение требований к их качеству и установке, недостаточность ширины дверных проемов, неудобные двери и дверные ручки, отсутствие перил, кнопок вызова, тактильных полос и тактильных табличек, наличие порогов и иных препятствий, недостаточность места для проезда и разворота инвалидных колясок перед входом в здания.

Что касается состояния пешеходных дорожек и тротуаров, в обследуемых населенных пунктах они лучше оборудованы для лиц с инвалидностью на центральных улицах. Состояние дорожек дворовых территорий, периферийных улиц и окраин чаще неудовлетворительное. Существенная проблема большинства тротуаров - отсутствие съездов с бордюров, в том числе на пешеходных переходах. В сельских поселениях также наиболее распространенной проблемой является наличие грунтовых, незаасфальтированных дорожек, неровный рельеф местности, что не позволяет проехать инвалидным коляскам.

Обобщая результаты наблюдения, можно заключить, что в Мурманской области социальносредовые барьеры для инвалидов существуют во всех сферах деятельности. Социальная инфраструктура городов и сельских поселений региона не соответствует требованиям доступности для людей с инвалидностью в полной мере ни в одной из сфер. При этом в городах для людей с инвалидностью в большей мере подготовлены учреждения социальной защиты населения (приоритетная сфера), банки и почтовые отделения (не относятся к приоритетным), в селах - только учреждения здравоохранения. В половине случаев доступны учреждения социальной защиты в сельских поселениях и транспорта в городских и сельских населенных пунктах. Все остальные сферы жизнедеятельности готовы для инвалидов в меньшей мере. Организация доступной среды в сельских поселениях значительно хуже городской, что подтверждает выдвинутую гипотезу.

Таким образом, процессы преобразования социальной среды в Мурманской области осуществляются крайне неравномерно по разным типам населенных пунктов. Отставание сел от инклюзивных преобразований среды может быть объяснено периферийностью расположения сельских поселений, приоритетом развития городской среды Мурманской области как высоко урбанизированного региона, недостаточностью финансирования, низкими темпами социальных преобразований по обеспечению независимой жизни людям с инвалидностью. Все это указывает на необходимость осуществления целенаправленных мер по преобразованию объектов социальной инфраструктуры в направлении организации доступной среды как в городских, так и в сельских поселениях. Указанные преобразования не только дадут возможность людям с инвалидностью реализовывать свои гражданские права наравне со здоровыми согражданами, но и улучшат уровень комфортности территорий для всех категорий населения.

\section{Ссылки и примечания:}

1. Статья подготовлена при поддержке Российского фонда фундаментальных исследований, грант № 18-011-00712.

2. Всемирная программа действий в отношении инвалидов [Электронный ресурс] : принята резолюцией $37 / 52$ Генеральной Ассамблеи от 3 дек. 1982 г. // OOH. URL: https://www.un.org/ru/documents/decl_conv/conventions/prog1.shtml (дата обращения: 15.08.2019). 
3. Конвенция о правах инвалидов [Электронный ресурс] : принята резолюцией 61/106 Генеральной Ассамблеи от 13 дек. 2006 г. // Там же. URL: https://www.un.org/ru/documents/decl_conv/conventions/disability.shtml (дата обращения: 15.08.2019).

4. Кабакович Г.А., Полежаева К.В. Влияние социальных и правовых барьеров на роль и место инвалидов в обществе // Вестник Башкирского университета. 2015. Т. 20, № 2. С. 635-644.

5. Фефелов В.А. В СССР инвалидов нет!.. Лондон, 1986. 169 с.

6. О ратификации Конвенции о правах инвалидов [Электронный ресурс] : федер. закон от 3 мая 2012 г. № 46-Ф3. Доступ из информ.-правового портала «Гарант».

7. О внесении изменений в отдельные законодательные акты Российской Федерации по вопросам социальной защиты инвалидов в связи с ратификацией Конвенции о правах инвалидов [Электронный ресурс] : федер. закон от 1 дек. 2014 г. № 419-Ф3 : с изм. и доп. Доступ из информ.-правового портала «Гарант».

8. Порядок обеспечения условий доступности для инвалидов объектов и предоставляемых услуг в сфере труда, занятости и социальной защиты населения, а также оказания им при этом необходимой помощи [Электронный ресурс] : приказ Минтруда России от 30 июля 2015 г. № 527н. Доступ из информ.-правового портала «Гарант».

9. О социальной защите инвалидов в Российской Федерации [Электронный ресурс] : федер. закон от 24 нояб. 1995 г. № 181-Ф3 : ред. от 18 июля 2019 г. Доступ из справ.-правовой системы «КонсультантПлюс».

10. Об утверждении государственной программы Российской Федерации «Доступная среда» [Электронный ресурс] : постановление Правительства РФ от 29 марта 2019 г. № 363. Доступ из информ.-правового портала «Гарант».

11. Жигунова Г.В., Афонькина Ю.А. Состояние социальной инклюзии людей с инвалидностью в современном обществе // Научное мнение. Экономические, юридические и социологические науки. 2018. № 4. С. $20-26$. https://doi.org/10.25807/РBН.25419838.2018.4.20.26.

12. Никонова А.А. Социологический анализ формирования безбарьерной среды для людей с инвалидностью (на примере категории слабовидящих и незрячих инвалидов) : автореф. дис. ... канд. социол. наук. Казань, 2015.23 с.

13. Шабунова А.А., Фахрадова Л.Н. Доступность городской среды для лиц с ограниченными возможностями // Вопросы территориального развития. 2014. № 3 (13). С. 2-15.

14. Там же. С. 11

15. Bates Ch. Conviviality, Disability and Design in the City // Sociological Review. 2018. Vol. 66, iss. 5. P. 984-999. https://doi.org/10.1177/0038026118771291.

16. Численность населения по муниципальным образованиям Мурманской области на 1 января 2019 г. и в среднем за 2018 г. [Электронный ресурс] // Мурманскстат : сайт. URL: https://murmanskstat.gks.ru/storage/mediabank/05034_2019.xls (дата обращения: 14.06.2019).

17. Численность детей-инвалидов [Электронный ресурс] // Федеральный реестр инвалидов : сайт. URL: https://sfri.ru/analitika/chislennost/chislennost-detei?territory=47000000 (дата обращения: 20.08.2019).

\section{References:}

Bates, Ch 2018 'Conviviality, Disability and Design in the City', Sociological Review, vol. 66, iss. 5, pp. 984-999, https://doi.org/10.1177/0038026118771291.

Fefelov, VA 1986, There are No Disabled People in the USSR!, London, 169 p., (in Russian).

Kabakovich, GA \& Polezhaeva, KV 2015, 'Influence of Social and Legal Barriers on the Role and Place of People With Disabilities in the Society', Vestnik Bashkirskogo universiteta, vol. 20, no. 2, pp. 635-644, (in Russian).

Nikonova, AA 2015, Sociological Analysis of Developing a Barrier-Free Environment for People With Disabilities (as Exemplified by the Category of the Blind and Visually Impaired), PhD thesis abstract, Kazan, 23 p., (in Russian).

Shabunova, AA \& Fakhradova, LN 2014, 'Accessibility of Urban Environment for People With Disabilities', Voprosy territorialnogo razvitia, no. 3 (13), pp. 2-15, (in Russian).

Zhigunova, GV \& Afonkina, YUA 2018, 'Social Inclusion of People With Disabilities in Modern Society', Nauchnoe mnenie. Ekonomicheskie, yuridicheskie i sotsiologicheskie nauki, no. 4. pp. 20-26, https://doi.org/10.25807/PBH.25419838.2018.4.20.26, (in Russian).

Редактор: Смирнова Светлана Леонидовна Переводчик: Герасимова Валентина Евгеньевна 